\title{
Diagnosis and prognosis of myocardial infarction in a patient without obstructive coronary artery disease during bronchoscopy: a case study and literature review
}

\author{
Menghuan Li, Yang Liu and Hui Wang ${ }^{*}$
}

\begin{abstract}
Background: It is increasingly recognized that a significant proportion of patients suffered from acute myocardial infraction (AMI) who did not have obstructive coronary artery disease ( $\geq 50 \%$ diameter stenosis). The term "MINOCA (myocardial infarction with nonobstructive coronary arteries)" was coined for such entity, however, the exact mechanism of MINOCA is still unclear. Herein, we report a patient with MINOCA during bronchoscopy and further review the recent literature.

Case presentation: A 65-year-old woman was hospitalized with the main complaint of chest tightness, nausea and vomiting for 30 min during bronchoscopy under local anesthesia. Immediate electrocardiogram (ECG) showed STsegments elevation in leads V2-6 compared with those at admission, and the further evolvement of leads V2-3 into pathological Q wave. Serum cardiac biomarkers revealed high-sensitive cardiac troponin T (hs-cTnT) levels of $20.12 \mathrm{ng} / \mathrm{L}$ and $674.6 \mathrm{ng} / \mathrm{L}$ at the peak (normal range 0-14 ng/L). Emergency coronary angiography (CAG) showed only approximate 30\% stenosis in the left anterior descending (LAD) ostium and $40 \%$ stenosis in the first diagonal branch (D1), with quantitative flow ratio (QFR) value for LAD of 0.96. Moreover, her echocardiographic examination presented new significant abnormal wall motion (anterior ventricular wall) with an estimated left ventricular ejection fraction (LVEF) of $62.1 \%$ after the cardiac attack. Thoracic enhanced CT scanning indicated no obvious sign of pulmonary embolism. Therefore, with confirmed AMI and the absence of significant coronary stenosis simultaneously, MINOCA was diagnosed with the prescription of dual-antiplatelet, statins, beta-blocker, angiotensin receptors antagonist, calcium channel blocker and nitrate. This patient had a good prognosis during a follow-up of 14 months.

Conclusion: In this case, bronchoscopy might have caused extremely tense and anxious which led to a sympathetic hyperfunction and acute coronary thrombosis induced by plaque disruption and coronary artery spasm. QFR value is a feasible technique to evaluate the functional coronary stenosis and assist the diagnose of MINOCA. Also, the diagnosis of MINOCA deems an exploration of underlying causes for proper management and prognostic evaluation.
\end{abstract}

Keywords: Myocardial infarction, Myocardial infarction in the absence of obstructive coronary artery disease (MINOCA), Bronchoscopy, Case study

\footnotetext{
*Correspondence: Wangnuo@188.com

The First Affiliated Hospital of Nanjing Medical University, Guangzhou Road No.300, Nanjing 210029, China
} 


\section{Background}

Acute myocardial infarction (AMI) is a life-threatening disease which requires urgent intervention. It has been proven that arteriosclerosis is a critical pathogenesis of AMI [1]. However, there are significant proportion of patients who will develop AMI without obstructive coronary artery disease ( $\geq 50 \%$ diameter stenosis). The term "MINOCA (myocardial infarction with nonobstructive coronary arteries)" was recently coined for such entity. It is characterized by changes of electrocardiography and elevation of cardiac biomarkers, as well as non-obvious angiographic coronary artery stenosis [2]. MINOCA is found in about $5-6 \%$ of all patients with AMI confirmed by coronary angiography (CAG). For the heterogenetic patients of MINCOA, although the underlying pathophysiological mechanisms are poorly understood, several possible mechanisms were proposed, including plaque disruption, coronary artery spasm, in-situ thrombosis, spontaneous coronary artery dissection, type $2 \mathrm{MI}$ and microvascular dysfunction [3]. It is vital to exclude other possible causes for troponin elevation, such as Takotsubo cardiomyopathy, myocarditis, pulmonary embolism, etc. As a local anesthesia procedure, bronchoscopy could cause certain stress for patients, but the overall severe cardiovascular complications during bronchoscopy are rare [4]. There are limited cases of AMI during bronchoscopy in previous literature. In this report, we present a case of MINOCA during bronchoscopy.

\section{Case presentation}

A 65-year-old woman who underwent right upper lung adenocarcinoma resection for 4 months and was found to have an elevated carcinoembryonic antigen (CEA) 2 days before admission. In order to determine whether the tumor had local recurrence, the bronchoscopy examination was scheduled. She had a history of hypertension for a year and did not take medication. No history of other chronic diseases such as diabetes, coronary artery disease (CAD) or stroke, and no history of cigarettes, alcohol or substance abuse were reported. Physical examination showed normal BMI of $22.73 \mathrm{~kg} / \mathrm{m}^{2}$ without other significant findings.

During the procedure, she had a sudden onset of chest tightness, nausea and vomiting for half an hour. An elevated blood pressure of $166 / 94 \mathrm{mmHg}$ without other novel abnormal signs was found in the examination. Immediate electrocardiogram (ECG) showed ST-segments elevation in leads V2-6 compared with those at admission, then the further evolvement of leads V2-3 into pathological Q wave (Fig. 1). Laboratory result revealed high-sensitive cardiac troponin $\mathrm{T}$ (hs-cTnT) levels of $20.12 \mathrm{ng} / \mathrm{L}$ and $674.6 \mathrm{ng} / \mathrm{L}$ at the peak (normal range 0$14 \mathrm{ng} / \mathrm{L}$ ). Moreover, her total cholesterol level was 6.70 $\mathrm{mmol} / \mathrm{L}$ (normal range $3.00-5.70 \mathrm{mmol} / \mathrm{L}$ ), low-density- lipoprotein cholesterol (LDL-C) level was $4.18 \mathrm{mmol} / \mathrm{L}$ (normal range $2.60-4.10 \mathrm{mmol} / \mathrm{L}$ ), and lipoprotein (LP a) level was $1223 \mathrm{mg} / \mathrm{L}$ (normal range $0-300 \mathrm{mg} / \mathrm{L}$ ). While other laboratory tests including routine complete blood count, urine test, glucose levels, renal and liver function, coagulation factors, hemoglobin A1c, thyroid function and autoimmune indicators were within the normal ranges. Thoracic enhanced CT scanning indicated no obvious sign of pulmonary embolism. Her echocardiographic examination presented new significant abnormal wall motion (anterior ventricular wall) with an estimated left ventricular ejection fraction (LVEF) of $62.1 \%$.

The patient had atypical angina symptoms, dynamic changes of ECGs and elevated cardiac biomarker. Her echocardiographic showed new significant abnormalities in the wall motion. Emergency CAG was performed and showed only approximate $30 \%$ stenosis in the left anterior descending (LAD) ostium and $40 \%$ stenosis in the first diagonal branch (Fig. 2), functional quantitative flow ratio (QFR) value for LAD was 0.96 (Fig. 3). Combined with the above history and test results, the diagnosis of MINOCA was ultimately made with the suspected causes of stress-induced coronary artery spasm and plaque disruption.

She received dual anti-platelet therapy with daily lowdose aspirin for life and clopidogrel for 1 year. Considering her hyperlipidemia, statin and cholesterol absorption inhibitors were given. In addition, calcium channel blocker $(\mathrm{CCB})$ and nitrites were given to control coronary artery spasm. Angiotensin receptor antagonist (ARB) was also prescribed for her uncontrolled blood pressure.

During a regular outpatient follow up for 14 months, she did not suffer from angina pectoris again. In the latest visit, echocardiograph showed that a normal ventricular wall motion and the estimated LVEF had rose to 69.4\%. No major adverse cardiac events (MACE) including re-infarction, heart failure, stroke and all causes of death occurred during the period of follow-up.

\section{Discussion and conclusions}

MINOCA is prevalent in 5-6\% of all the AMI cases, and ranges from 5 to $15 \%$ depending on different studies [3]. The demographic and clinical features of MINOCA patients are different from those of AMI with obstructive coronary artery disease (AMI-CAD). MINOCA patients have a lower age and a higher incidence in women [5]. The fourth universal definition of myocardial infarction [6] demonstrated that AMI should be diagnosed with acute myocardial injury and myocardial ischemia simultaneously. Acute myocardial injury refers to the troponin $>99$ th percentile of the upper reference level with a rise or fall in the serial assessments. And myocardial ischemia refers to the following manifestations: symptoms of 

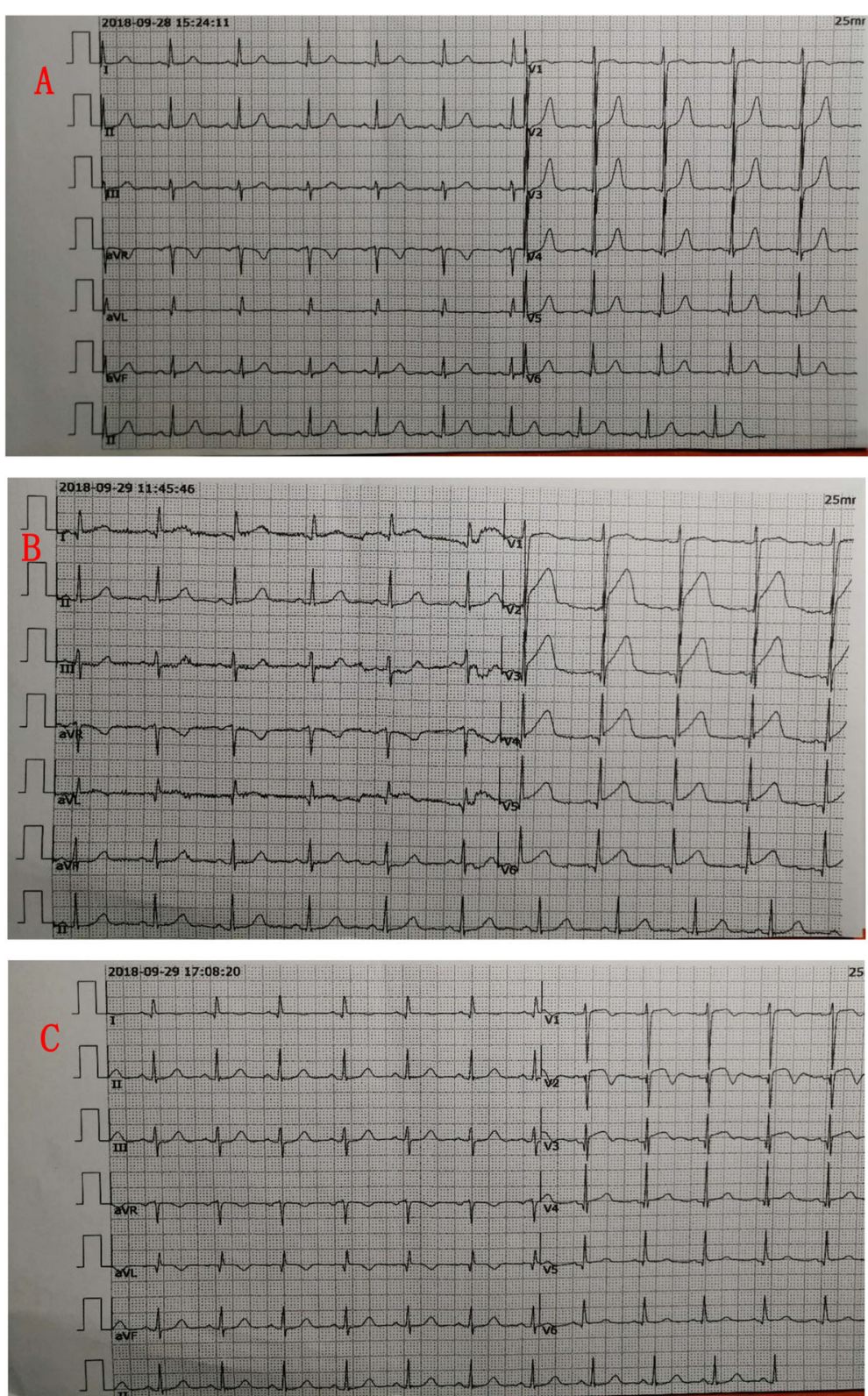

Fig. 1 Dynamic changes in electrocardiography during the acute myocardial infarction. a, Sinus rhythm, normal ECG. b. ST-segments elevation in leads V2-6 during the sudden onset of cardiac attack. c, Pathological Q waves in leads V2-3, ST-segments elevation in leads V1-4, T-waves inverted in lead $\mathrm{V} 1-3$ and $\mathrm{aVL}$

myocardial ischemia, new ECG changes of ischemia, new $\mathrm{Q}$ waves in ECG, imaging evidence of surviving myocardial loss and regional wall motion abnormalities, or coronary thrombosis found by CAG or autopsy.

MINOCA is a working diagnosis and other ischemic disease and nonischemic disease that can mimic AMI, including sepsis, myocarditis, pulmonary embolism, missed obstructive CAD and Takotsubo syndrome etc., should be excluded [3]. The patient did not have any evidence of infection, so sepsis was excluded. She denied the prodromal virus-infected symptoms, and ECG showed typical changes of ischemia, so myocarditis was out of consideration. Moreover, her Thoracic enhanced CT scanning indicated no obvious signs of pulmonary embolism. Imaging of her CAG was confirmed by two different cardiologists who ensured no missed obstructive lesions.

Bronchoscopy is a routine diagnostic and therapeutic technique which is wildly applied for various pulmonary diseases for decades. The overall incidence of severe complications is low $[4,7]$ and it is considered a safe procedure with proper pre-evaluation. The most common complications during bronchoscopy are local anesthesia- 


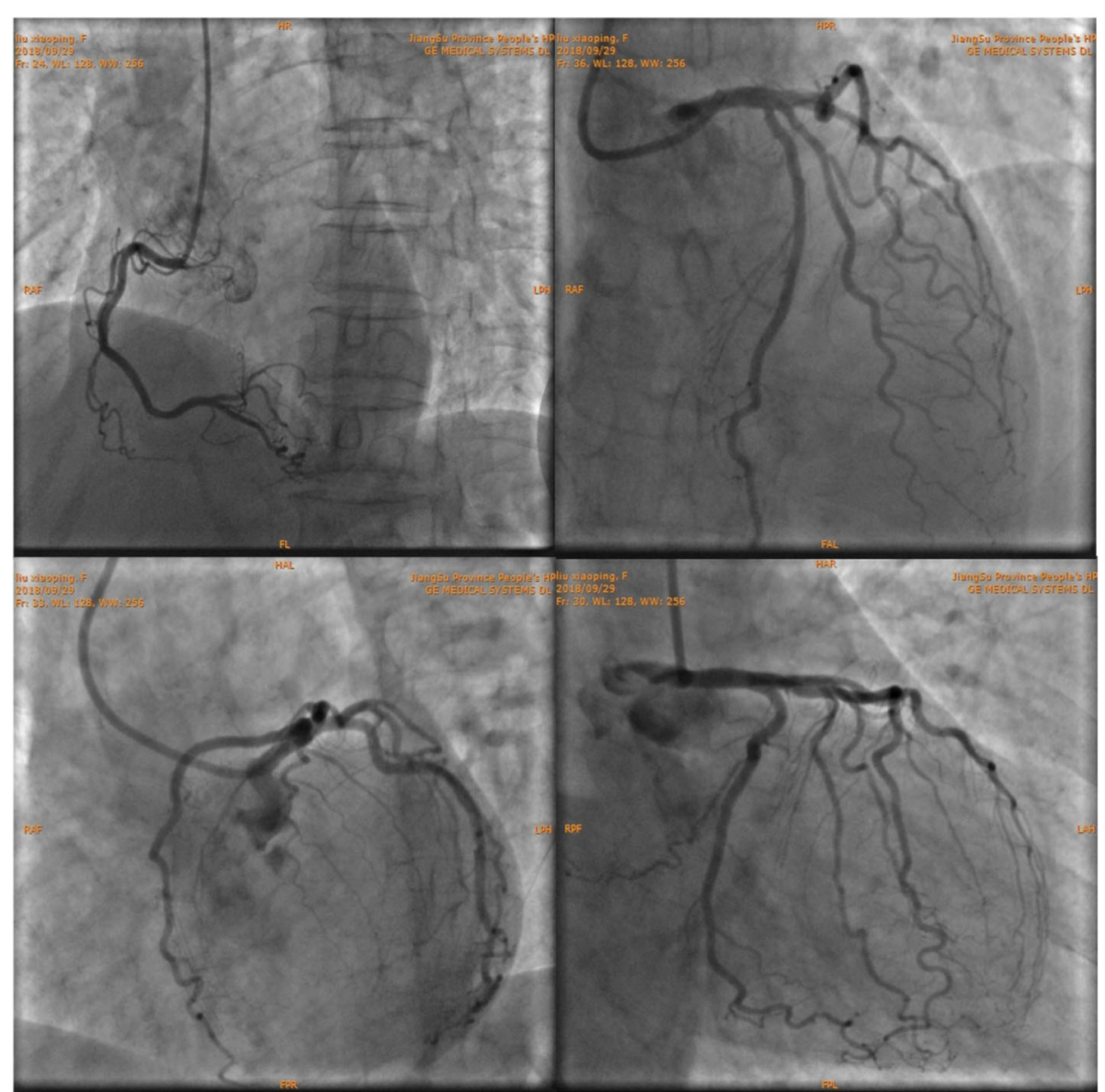

Fig. 2 Images of coronary angiography. Approximate 30\% stenosis in the left anterior descending (LAD) ostium and $40 \%$ stenosis in the first diagonal branch (D1)

related $(0.3-0.5 \%)$, hypoxemia $(0.2-21 \%)$, arrhythmias (1-10\%), bleeding following biopsy $(0.12-7.5 \%)$, pneumothorax or pneumomediastinum $(1-6 \%)$ and fever $(0.9-2.5 \%)$ [8]. Serious cardiac attacks associated with bronchoscopy are rare.

There are a few reports of takotsubo cardiomyopathy induced by flexible bronchoscopy which may be attributed to over-released catecholamines due to the extreme stress [9-12]. The manifestation of Takotsubo syndrome could be similar to AMI, and it is characterized by transient left ventricular dysfunction and ballooning of the apical part of the left ventricular with reduced LVEF [13, 14]. This patient was an elder woman who had a history of lung cancer resection and underwent bronchoscopy for checkup. During the procedure, she had atypical symptoms of myocardial ischemia, dynamic elevated cardiac biomarkers, typical ST-T changes and Q waves in ECG. However, no abnormalities at the apical part and impaired function of left ventricular were observed on her echocardiography. According to the fourth universal definition of myocardial infarction, we made a definite diagnose of
AMI. Subsequent CAG showed no significant obstructive stenosis, thus we confirmed a diagnosis of MINOCA.

Epicardial coronary vasospasm can occur either in response to drugs or toxin that result in hyper-reactive of vascular smooth muscles, or in the disorders of coronary vasomotor tone [3]. These prolonged coronary vasospastic episodes can eventually lead to MINOCA. In one study, vasospasm occurred in $46 \%$ of the MINOCA patients who underwent provocative testing [15]. We believed that the patient might be in excessive stressed condition during the bronchoscopy, which trigger an excessive release of catecholamine causing severe and prolonged vasomotor dysfunction. The diagnosis of coronary vasospasm requires administration of intracoronary acetylcholine (Ach) and evaluation from invasive coronary angiography [16]. However, there are only limited experiences of Ach test in MINOCA patients. Furthermore, provocative spasm testing is seldom performed in China due to the scarce supply of Ach.

Coronary artery plaque disruption can trigger thrombus formation that results in AMI through distal embolization, or in some cases, transient complete in-situ thrombosis 

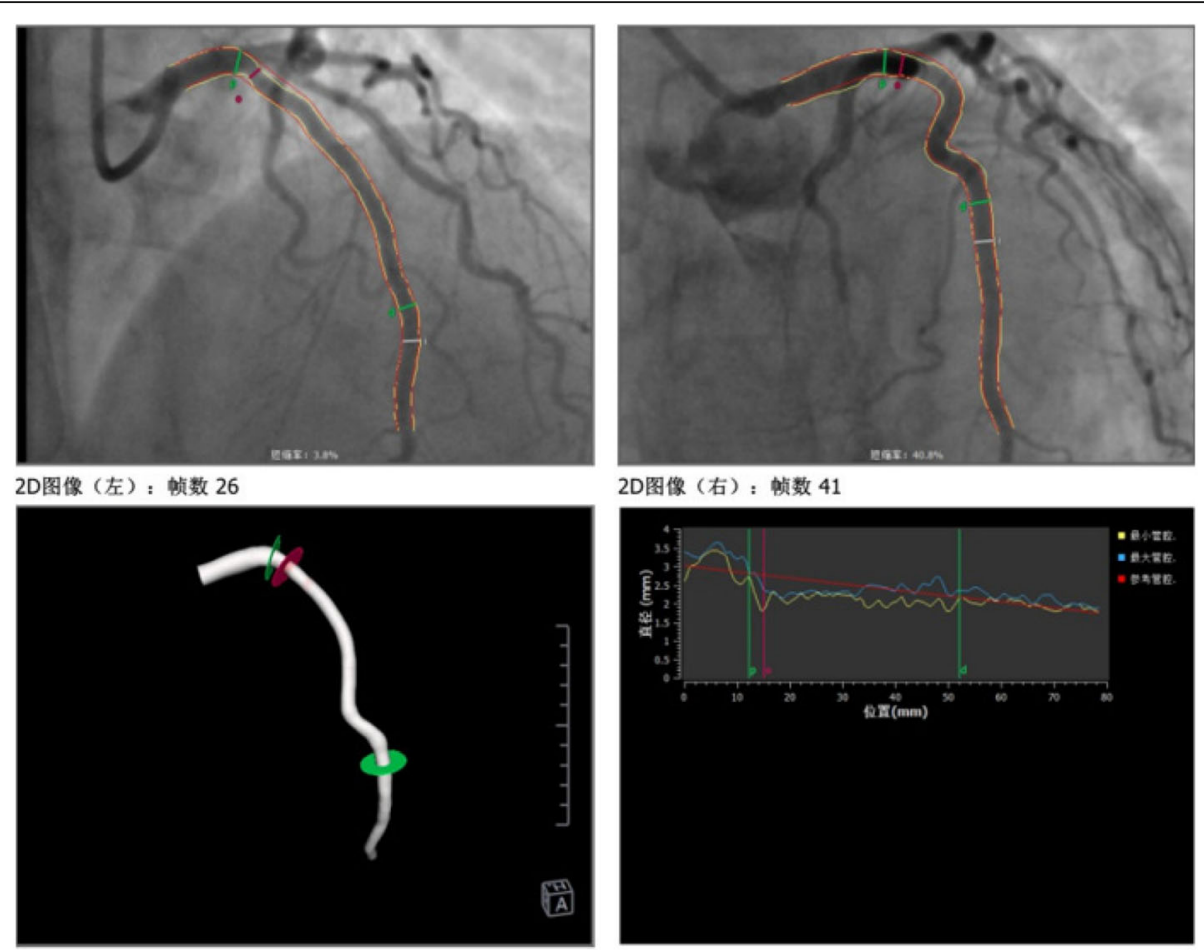

直径曲线图
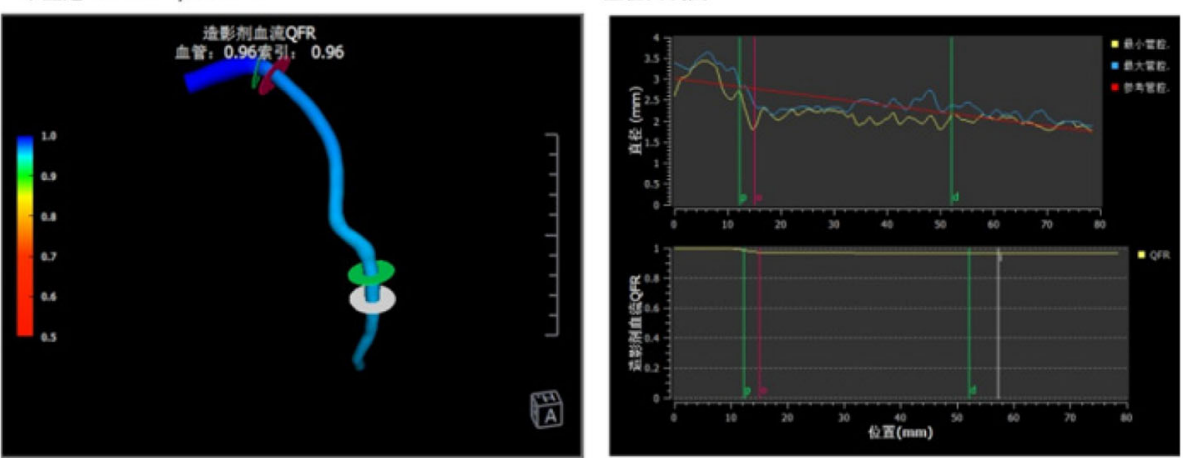

三维重建QFR

直径和QFR曲线图

Fig. 3 QFR value of left anterior descending (LAD). Based on the three-dimensional images from CAG and principles of fluid dynamics, QFR value of the target vessel - LAD was 0.96

with spontaneous thrombolysis. Ouldzein et al. reported approximately $34 \%$ of plague rupture in a cohort of 68 patients with MINOCA [17]. The only definite diagnosis tool for plague disruption is intracoronary imaging, such as the higher-resolution optical coherence tomography (OCT) or intravascular ultrasound (IVUS). The underlying cause of this case was probably contributed to plague disruption, leading to acute thrombosis with spontaneous thrombolysis. Unfortunately, we have not been able to perform intracoronary imaging to figure out the possible mechanism, due to the cost and invasive method.

Fractional flow reserve (FFR) is a gold method to evaluate functional coronary stenosis, which was recommended in a scientific statement about MINOCA from American Heart Association (AHA) [3]. In recent years, quantitative flow ratio (QFR) has been validated as an accurate surrogate and showed an excellent diagnostic value for functional coronary stenosis compared with FFR [18-21]. Although our patient did not undergo provocative testing and intracoronary imaging for the assessment above, QFR was performed on the lesion of left anterior descending (LAD) as the alternative method which showed no significant functional stenosis of LAD supporting the diagnosis of MINOCA.

Previous studies had reported that dual anti-platelet agents had an incremental benefit to MINOCA patients with plaque disruption [22, 23]. Based on the results above, we prescribed her with aspirin and clopidogrel. Additionally, it was documented that $\mathrm{CCB}$ and shortacting nitrates were able to suppress the angina 
symptoms in vasospastic angina patients [16, 24], so $\mathrm{CCB}$ and nitrates were also prescribed. Angiotensin converting enzyme inhibitors (ACEI) /ARB and statin showed great cardioprotective effects for MINOCA patients [2], and thus both ARB and statin therapies were given as well. In one-year follow-up, the patient did not suffer from heart failure with a great recovery of ejection fraction.

Traditional risk factors for CAD are less prevalent in MINOCA patients, such as hypertension, hyperlipidemia, diabetes mellitus, smoking and drinking [25]. The patients of this case had two risk factors of hypertension and hyperlipidemia. The prognosis of MINOCA patients differed from those in many studies. Compared with AMI-CAD patients, most patients with MINOCA had a better prognosis $[5,26]$. ACTION-Registry-GWTG study demonstrated that in-hospital mortality rate and MACE rate of MINOCA patients were lower than those of AMI-CAD patients [5]. However, VIGRO study indicated a similar 1-month and 1-year mortality rate between MONOCA and AMI-CAD patients [25]. ST segment elevation, heart failure or cardiac shock were independent predictors for in-hospital mortality rate [5]. However, it is worth mentioning that there was a lack of correlation between different etiologies in MINOCA patients.

The bronchoscopy might have caused extremely tense and anxious which led to a sympathetic hyperfunction and acute transient coronary thrombosis induced by plaque disruption and coronary artery spasm. The diagnosis of the MINOCA was considered according to the confirmed AMI and the absence of significant coronary stenosis simultaneously. And its diagnosis algorithm is so comprehensive that various diseases that mimic AMI should be excluded and underlying causes should be sought. QFR might be an efficient approach for the assessment of coronary artery. Overall, patients with MINOCA seems to have a better prognosis than those of AMI patients with obstructive coronary stenosis, which large cohort clinical trial is needed for further exploration of these heterogeneities.

\section{Abbreviations}

MINOCA: Myocardial infarction with no obstructive coronary artery disease; ECG: Electrocardiogram; CAG: Coronary angiography; LAD: Left anterior descending; D1: The first diagonal branch; LVEF: Left ventricular ejection fraction; hs-cTnT: High-sensitive cardiac troponin T; ACEl: Angiotensin converting enzyme inhibitors; ARB: Angiotensin receptors antagonist; CCB: Calcium channel blocker; AMI: Acute myocardial infarction; CEA: Carcinoembryonic antigen; MACE: Major adverse cardiac events; CAD: Coronary artery disease; QFR: Quantitative flow ratio; CT: Computed tomography; LDL-C: Low-density-lipoprotein cholesterol; LP a: Lipoprotein a; Ach: Acetylcholine; OCT: Optical coherence tomography; IVUS: Intravascular ultrasound; AHA: American Heart Association; FFR: Fractional flow reserve
\end{abstract}

\section{Acknowledgements}

Authors would like to appreciate Dr. lokfai Cheang (The First Affiliated Hospital of Nanjing Medical University) for his kind language editing service.

\section{Authors' contributions}

$\mathrm{MH} L$ was involved in compilation of data and the major contributor writing the manuscript. $Y L$ was responsible for the clinical follow-up care. $H$ W was the chief consultant author involved in the management of the case. All the authors have read and approved the submitted manuscript.

\section{Funding}

This paper was funded by "Natural Science Foundation of Jiangsu Provincial (BK2012648 to Hui Wang)" and "Six talent peaks" project in Jiangsu Province (2015-WSN-033)". The funding body played no role in the design, writing or decision to publish this manuscript.

\section{Availability of data and materials}

The data analyzed in the case report are not publicly available due to the privacy policy of the hospital but are available from the corresponding author on reasonable request.

\section{Ethics approval and consent to participate}

Not applicable.

\section{Consent for publication}

Written informed consent was obtained from the patient for publication of this case report and any accompanying images. A copy of the written consent is available for review by the Editor-in-Chief of this journal.

\section{Competing interests}

The authors declare that they have no competing interests.

Received: 15 January 2020 Accepted: 1 April 2020

Published online: 21 April 2020

References

1. DeWood MA, Stifter WF, Simpson CS, Spores J, Eugster GS, Judge TP, Hinnen ML. Coronary Arteriographic Findings Soon after Non-Q-Wave Myocardial Infarction. N Engl J Med. 1986;315(7):417-23.

2. Lindahl B, Baron T, Erlinge D, Hadziosmanovic N, Nordenskjold A, Gard A, Jernberg $T$. Medical therapy for secondary prevention and long-term outcome in patients with myocardial infarction with nonobstructive coronary artery disease. Circulation. 2017;135(16):1481-9.

3. Tamis-Holland JE, Jneid H, Reynolds HR, Agewall S, Brilakis ES, Brown TM, Lerman A, Cushman M, Kumbhani DJ, Arslanian-Engoren C, Bolger AF, Beltrame JF. Contemporary diagnosis and Management of Patients with Myocardial Infarction in the absence of obstructive coronary artery disease: a scientific statement from the American Heart Association [J]. Circulation. 2019.

4. Pue CA, Pacht ER. Complications of Fiberoptic bronchoscopy at a university hospital[J]. Chest. 1995:107(2):430-2.

5. Smilowitz NR, Mahajan AM, Roe MT, Hellkamp AS, Chiswell K, Gulati M, Reynolds HR. Mortality of myocardial infarction by sex, age, and obstructive coronary artery disease status in the ACTION registry-GWTG (acute coronary treatment and intervention outcomes network registry-get with the guidelines). Circ Cardiovasc Qual Outcomes. 2017;10:e003443.

6. Thygesen K, Alpert JS, Jaffe AS, Chaitman BR, Bax JJ, Morrow DA, White HD. The executive group on behalf of the joint European Society of Cardiology (ESC)/American College of Cardiology (ACC)/American Heart Association (AHA)/world heart federation (WHF) task force for the universal definition of myocardial infarction. Fourth universal definition of myocardial infarction (2018). Circulation. 2018;138:e618-51.

7. Davies L, Mister R, Spence DP, Calverley PM, Earis JE, Pearson MG. Cardiovascular consequences of fiberoptic bronchoscopy. Eur Respir J. 1997; 10(3):695-8.

8. Geraci G, Pisello F, Sciumè C, Li Volsi F, Romeo M, Modica G. Complication of flexible fiberoptic bronchoscopy. Literature review [Article in Italian]. Ann Ital Chir. 2007;78(3):18392.

9. Badovinac S, Korsic M, Cucevic B, Slivnjak V, Dugac AV, Jakopovic M. Stress cardiomyopathy following acute ischemic stroke during flexible bronchoscopy: a rare sequence of complications[]]. J Bras Pneumol. 2013;39.

10. Miyoshi S, Takeda Y, Ro S, Masaki H, Hojo M, Sugiyama H. Takotsubo cardiomyopathy and subsequent seizures induced by flexible bronchoscopy. Respir Care. 2015;60(9):e151-4. 
11. Ok KS, Song BG, Park KS, Jung HG, Jung HJ, Park IN, Yum HK, Cho WH, Choi SK. Inverted Tako-Tsubo cardiomyopathy associated with bronchoalveolar lavage. Heart Lung Circ. 2011 Jul;20(7):476-8.

12. Guerrero J, Majid A, Ernst A. Cardiogenic Shock Secondary to Tako-tsubo Syndrome After Debridement of Malignant Endobronchial Obstruction. Chest. 135(1):217-20.

13. Komamura K. Takotsubo cardiomyopathy: Pathophysiology, diagnosis and treatment. World J Cardiol. 2014;(7):6.

14. Pasupula DK, Patthipati VS, Javed A, Siddappa Malleshappa SK. Takotsubo cardiomyopathy: understanding the pathophysiology of selective left ventricular involvement. Cureus. 2019;11(10)::5972.

15. Montone RA, Niccoli G, Fracassi F, Russo M, Gurgoglione F, Cammà G, Lanza GA, Crea F. Patients with acute myocardial infarction and nonobstructive coronary arteries: safety and prognostic relevance of invasive coronary provocative tests. Eur Heart J. 2018;39:91-8.

16. Beltrame JF, Crea F, Kaski JC, Ogawa H, Ong P, Sechtem U, Shimokawa H, Bairey Merz CN. On behalf of the Coronary Vasomotion Disorders International Study Group (COVADIS). The who, what, why, when, how and where of vasospastic angina. Circ J. 2016;80:289-98.

17. Ouldzein H, Elbaz M, Roncalli J, Cagnac R, Carrié D, Puel J, Alibelli-Chemarin $\mathrm{MJ}$. Plaque rupture and morphological characteristics of the culprit lesion in acute coronary syndromes without significant angiographic lesion: analysis by intravascular ultrasound. Ann Cardiol Angeiol (Paris). 2012;61:20-6.

18. Tu S, Westra J, Yang J, et al. Diagnostic accuracy of fast computational approaches to derive fractional flow reserve from diagnostic coronary angiography: the international multicenter FAVOR pilot study. JACC Cardiovasc Interv. 2016;9(19):2024-35.

19. Xu B, Tu S, Qiao S, et al. Diagnostic accuracy of angiography-based quantitative flow ratio measurements for online assessment of coronary stenosis. J Am Coll Cardiol. 2017;70(25):3077-87.

20. Westra J, Andersen BK, Campo G, et al. Diagnostic Performance of InProcedure Angiography-Derived Quantitative Flow Reserve Compared to Pressure-Derived Fractional Flow Reserve: The FAVOR II Europe-Japan Study. J Am Heart Assoc. 2018;7(14):e009603 Published 2018 Jul 6.

21. Westra J, Tu S, Winther $\mathrm{S}$, et al. Evaluation of coronary artery stenosis by quantitative flow ratio during invasive coronary angiography: the WIFI II study (wire-free functional imaging II). Circ Cardiovasc Imaging. 2018;11(3): e007107.

22. Chen ZM, Jiang LX, Chen YP, Xie JX, Pan HC, Peto R, Collins R, Liu LS. COMMIT (ClOpidogrel and Metoprolol in Myocardial Infarction Trial) collaborative group. Addition of clopidogrel to aspirin in 45,852 patients with acute myocardial infarction: randomised placebo-controlled trial. Lancet. 2005;366:1607-21.

23. Xing L, Yamamoto E, Sugiyama T, Jia H, Ma L, Hu S, Wang C, Zhu Y, Li L, Xu M, Liu H, Bryniarski K, Hou J, Zhang S, Lee H, Yu B, Jang IK. EROSION study (effective anti-thrombotic therapy without stenting: intravascular optical coherence tomography-based Management in Plaque Erosion): a 1-year follow-up report. Circ Cardiovasc Interv. 2017:10:e005860.

24. Chahine RA, Feldman RL, Giles TD, Nicod P, Raizner AE, Weiss RJ, Vanov SK. Amlodipine study 160 group. Randomized placebo-controlled trial of amlodipine in vasospastic angina. J Am Coll Cardiol. 1993;21:1365-70.

25. Safdar B, Spatz ES, Dreyer RP, Beltrame JF, Lichtman JH, Spertus JA, Reynolds HR, Geda M, Bueno H, Dziura JD, Krumholz HM, D'Onofrio G. Presentation, clinical profile, and prognosis of young patients with myocardial infarction with nonobstructive coronary arteries (MINOCA): results from the VIRGO study. J Am Heart Assoc. 2018;7:e009174.

26. Pasupathy S, Air T, Dreyer RP, Tavella R, Beltrame JF. Systematic review of patients presenting with suspected myocardial infarction and nonobstructive coronary arteries [published correction appears in circulation. 2015;131:e475]. Circulation. 2015;131:861-70.

\section{Publisher's Note}

Springer Nature remains neutral with regard to jurisdictional claims in published maps and institutional affiliations.
Ready to submit your research? Choose BMC and benefit from:
- fast, convenient online submission
- thorough peer review by experienced researchers in your field
- rapid publication on acceptance
- support for research data, including large and complex data types
- gold Open Access which fosters wider collaboration and increased citations
- maximum visibility for your research: over $100 \mathrm{M}$ website views per year
At BMC, research is always in progress.
Learn more biomedcentral.com/submissions 